\title{
A new instrument for predicting survival of patients with cerebral metastases from breast cancer developed in a homogeneously treated cohort
}

\author{
Stefan Janssen ${ }^{1,2}$, Heinke C Hansen ${ }^{1}$, Liesa Dziggel ${ }^{1}$, Steven E Schild ${ }^{3}$, Dirk Rades ${ }^{1}$ \\ ${ }^{1}$ Department of Radiation Oncology, University Hospital Lubeck, Lubeck, Germany \\ ${ }^{2}$ Medical Practice for Radiotherapy and Radiation Oncology, Hannover, Germany \\ ${ }^{3}$ Department of Radiation Oncology, Mayo Clinic Scottsdale, Arizona, U.S.A.
}

Radiol Oncol 2019; 53(2): 219-224

Received 12 February 2019

Accepted 27 March 2019

Correspondence to: Dirk Rades, M.D., Chair of the Department of Radiation Oncology, University of Lübeck, Ratzeburger Allee 160, 23562 Lubeck, Germany. Phone: +49-451-500-45401; Fax: +49-451-500-45404; E-mail: dirk.rades@uksh.de

Disclosure: No potential conflicts of interest were disclosed.

Background. Previous survival scores for breast cancer patients with cerebral metastases were developed in cohorts receiving heterogeneous treatments, which could have introduced selection biases. A new instrument (WBRT-30-BC) was created from 170 patients receiving whole-brain radiotherapy (WBRT) alone with 30 Gy in 10 fractions.

Methods. Characteristics showing significant associations $(p<0.05)$ with overall survival (OS) or a trend $(p<0.08)$ on multivariate analysis were used for the WBRT-30-BC. For each characteristic, 6-month OS rates were divided by 10. These scoring points were added for each patient (patient scores). The WBRT-30-BC was compared to the diagnosisspecific graded prognostic assessment (DS-GPA) classification and Rades-Score for breast cancer regarding positive predictive values (PPVs) to identify patients dying within 6 months and patients surviving at least 6 months following WBRT.

Results. On multivariate analysis, Karnofsky performance score (KPS) was significant (risk ratio [RR]: 2.45, $p<0.001$ ). In addition, extra-cerebral metastatic disease (RR: 1.52, $\mathrm{p}=0.071$ ) and time between breast cancer diagnosis and WBRT (RR: 1.37, $p=0.070$ ) showed a trend. Based on these three characteristics, four predictive groups were designed: 7-9, $10-12,13-15$ and 16 points. Six-month OS rates were $8 \%, 41 \%, 68 \%$ and $100 \%$ ( $p<0.001$ ). PPVs to identify patients dying within 6 months were 92\% (WBRT-30-BC), 84\% (DS-GPA) and 92\% (Rades-Score). PPVs to identify patients surviving for at least 6 months were 100\% (WBRT-30-BC), 74\% (DS-GPA) and 68\% (Rades-Score).

Conclusions. The WBRT-30-BC appeared very accurate in predicting death $\leq 6$ months and survival $\geq 6$ months of breast cancer patients receiving WBRT. It was superior to previous instruments in predicting survival $\geq 6$ months.

Key words: breast cancer; cerebral metastases; whole-brain radiotherapy; overall survival time; diagnosis-specific predictive tool

\section{Introduction}

Breast cancer patients account for about $25 \%$ of patients developing cerebral metastases. ${ }^{1,2}$ A considerable proportion of these patients present with multiple lesions when the cerebral lesions are detected or a low performance score. These patients often receive whole-brain radiotherapy (WBRT) alone. Common WBRT-regimens include 20.0 Gy in 5 fractions (duration $=$ one week), $30.0 \mathrm{~Gy}$ in 10 fractions (two weeks), 35.0-37.5 Gy in 14-15 fractions (three weeks) and $40.0 \mathrm{~Gy}$ in 20 fractions (four weeks). ${ }^{1}$ In general, patients with a short expected overall survival (OS) time should receive a $20 \mathrm{~Gy}$ in 5 fractions, since this regimen was not inferior to $30 \mathrm{~Gy}$ in 10 fractions with respect to OS, local 
(= intracerebral) control and feasibility. ${ }^{3}$ For selected patients with a very poor prognosis, WBRT may be omitted, and supportive care alone can be administered instead. ${ }^{4}$ On the contrary, for patients with more favorable OS prognoses, i.e. a median OS time of longer than one year, improved outcomes were found for $40 \mathrm{~Gy}$ in 20 fractions when compared to $30 \mathrm{~Gy}$ in 10 fractions. ${ }^{5}$ Moreover, since patients of the latter group will likely live long enough to experience WBRT-associated late toxicities including neuro-cognitive impairment, WBRT should be given with doses per fraction of less than 3.0 Gy. ${ }^{6}$ In addition, hippocampal sparing and administration of memantine are helpful in preserving cognition. ${ }^{7,8}$

Thus, it is important to be able to judge an individual patient's OS prognosis to select the optimal WBRT-regimen. Several scoring systems were developed for patients to be treated for cerebral metastases. To go one step further and allow for even better personalization of treatment, separate scoring tools were created for single tumor entities spreading to the brain. ${ }^{9}$ This is an important approach, because the tumor entities vary considerably with respect to biological behaviour and prognoses. Such diagnosis-specific tools were already developed also for patients treated with WBRT for cerebral metastases from breast cancer..$^{9,10}$ However, these tools were designed from patients who had received heterogeneous treatment-regimens, including different WBRT-regimens with one or two daily fractions and the addition of chemotherapy, a

TABLE 1. Distribution of the patient characteristics

\begin{tabular}{|c|c|c|}
\hline Characteristic & $\begin{array}{l}\text { Number of } \\
\text { patients }\end{array}$ & $\begin{array}{l}\text { Proportion } \\
\text { (\%) }\end{array}$ \\
\hline $\begin{array}{l}\text { Age } \\
\leq 61 \text { years } \\
\geq 62 \text { years }\end{array}$ & $\begin{array}{l}85 \\
85\end{array}$ & $\begin{array}{l}50 \\
50\end{array}$ \\
\hline $\begin{array}{l}\text { Karnofsky performance score } \\
<>70 \% \\
70 \% \\
>70 \%\end{array}$ & $\begin{array}{l}76 \\
41 \\
53\end{array}$ & $\begin{array}{l}45 \\
24 \\
31\end{array}$ \\
\hline $\begin{array}{l}\text { Time between first diagnosis of bre } \\
\text { WBRT } \\
\leq 33 \text { months } \\
\geq 34 \text { months }\end{array}$ & $\begin{array}{l}85 \\
85\end{array}$ & $\begin{array}{l}50 \\
50\end{array}$ \\
\hline $\begin{array}{l}\text { Systemic treatment prior to WBRT } \\
\text { No } \\
\text { Yes }\end{array}$ & $\begin{array}{c}22 \\
148\end{array}$ & $\begin{array}{l}13 \\
87\end{array}$ \\
\hline $\begin{array}{l}\text { Number of cerebral lesions } \\
1-3 \\
\geq 4\end{array}$ & $\begin{array}{c}52 \\
118\end{array}$ & $\begin{array}{l}31 \\
69\end{array}$ \\
\hline $\begin{array}{l}\text { Controlled primary tumor } \\
\text { No } \\
\text { Yes }\end{array}$ & $\begin{array}{c}12 \\
158\end{array}$ & $\begin{array}{c}7 \\
93\end{array}$ \\
\hline $\begin{array}{l}\text { Extra-cerebral metastatic disease } \\
\text { No } \\
\text { Yes }\end{array}$ & $\begin{array}{c}38 \\
132\end{array}$ & $\begin{array}{l}22 \\
78\end{array}$ \\
\hline
\end{tabular}

radio-sensitizer or radiosurgery. This heterogeneity might have resulted in hidden biases. Therefore, this study was conducted and another scoring tool, the WBRT-30-BC, was created specifically for patients with cerebral metastases from breast cancer assigned to receive WBRT. In this study, all patients were homogeneously treated with 30 Gy in 10 fractions of WBRT alone. The new WBRT-30-BC was compared to two previous scoring tools that were also developed for estimating the OS of breast cancer patients with cerebral metastases.

\section{Patients and methods}

The data of 170 breast cancer patients receiving 30 Gy in 10 fractions of WBRT alone for cerebral metastases between 1994 and 2017 were retrospectively evaluated. The study was approved by the ethics committee of the University of Lübeck. Seven clinical pre-treatment characteristics were investigated for potential correlations with OS including age at WBRT ( $\leq 61$ vs. $\geq 62$ years, median age: 61.5 years), Karnofsky performance score (KPS) $(<70 \%$ vs. 70\% vs. $>70 \%)$, time between first diagnosis of breast cancer and WBRT ( $\leq 33$ vs. $\geq 34$ months, median time: 33.5 months), systemic treatment prior to WBRT (no vs. yes), number of cerebral lesions (1-3 vs. $\geq 4$ ), controlled primary tumor (no vs. yes) and presence of extra-cerebral metastatic disease (no vs. yes) (Table 1).

For all seven characteristics, univariate analyses were performed using the Kaplan-Meier method and the log-rank test. ${ }^{11}$ Characteristics with a pvalue of $<0.20$ on log-rank test, were additionally included in a multivariate analysis (Cox regression model). Those characteristics that showed a significant $(\mathrm{p}<0.05)$ association with OS or a trend $(\mathrm{p}<0.08)$ in the multivariate analysis were taken to create the new WBRT-30-BC score. For the development of the WBRT-30-BC, the same method was used as for the general WBRT-30 which was created from patients with different primary tumor types. ${ }^{12}$ For each characteristic included in the score, the 6-month OS rate (in \%) was divided by 10 to get the scoring points. The corresponding scoring points were added for each patient, and the patient scores were received. Based on the 6-month OS rates of the patient scores, prognostic groups were formed to estimate the 6-month OS probability of individual patients.

The new WBRT-30-BC was compared to two other diagnosis-specific tools that were developed for patients with cerebral metastases from breast 
TABLE 2. Univariate analyses of overall survival (OS); $p$-values were received from the Wilcoxon test.

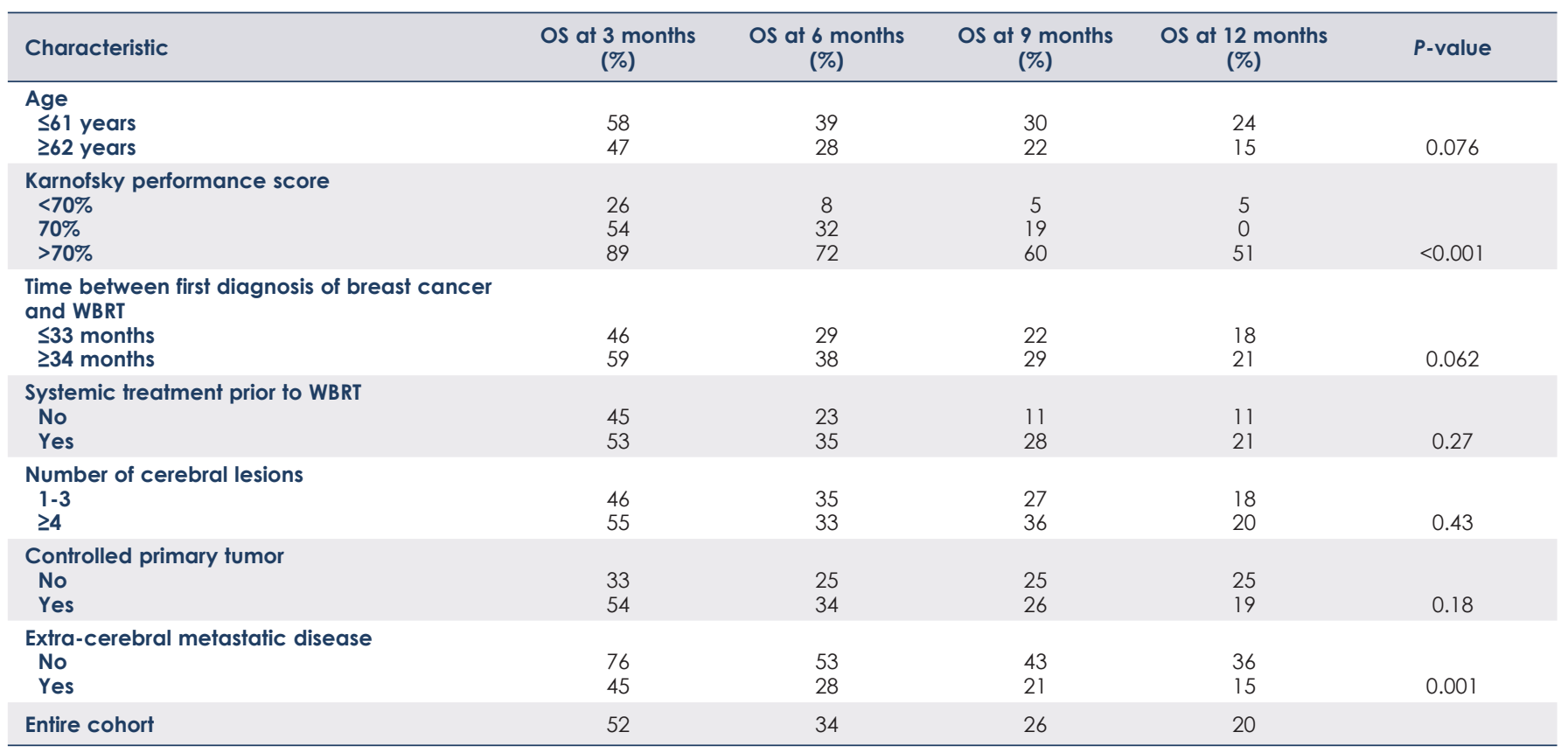

cancer. These tools included the diagnosis-specific graded prognostic assessment (DS-GPA) classification for breast cancer and the Rades-Score for brain metastases from breast cancer. 9,10 The DS-GPA consisted of four prognostic groups based on the KPS. These groups were $0.0-1.0$ points (KPS $\leq 70 \%$ ), 1.5-2.5 (KPS 80\%), 3.0 (KPS 90\%) and 3.5-4.0 (KPS $100 \%) .{ }^{9}$ The Rades-Score was based on KPS (<70\%: 1 point, $\geq 70 \%$ : 6 points) and extra-cerebral metastases (yes: 3 points, no: 6 points) and included three prognostic groups (4-7 points, 9 points and 12 points). ${ }^{10}$

The WBRT-30-BC and the other two scores were compared regarding the positive predictive values (PPVs) for identification of patients dying within 6 months (poor prognosis groups) and of patients surviving at least 6 months (favorable prognosis groups) following WBRT. Both PPVs were calculated by dividing the number of true positives by (number of true positives + number of false positives).

\section{Results}

On univariate analyses (Table 2), better OS was significantly associated with KPS $>70 \%(p<0.001)$ and absence of extra-cerebral metastases $(\mathrm{p}=$ $0.006)$. In addition, for age $\leq 61$ years $(p=0.097)$, time between first diagnosis of breast cancer and
WBRT $\geq 34$ months $(\mathrm{p}=0.19)$ and systemic treatment prior to WBRT $(\mathrm{p}=0.17)$, $\mathrm{p}$-values $<0.20$ were found. These five characteristics were included in the Cox regression analysis, in which KPS was significant (risk ratio [RR]: 2.45; 95\%-confidence interval [CI]: 1.93-3.13; $\mathrm{p}<0.001)$. In addition, the time between diagnosis of breast cancer and WBRT (RR: 1.37; 95\% CI: 0.97-1.94; $p=0.070)$ and extra-cerebral metastatic disease (RR: 1.52; 95\% CI: 0.97-2.48; $\mathrm{p}=0.071)$ showed a trend. Age (RR: $1.19 ; 95 \% \mathrm{CI}$ : $0.84-1.67 ; \mathrm{p}=0.33)$ and systemic treatment prior to WBRT (RR: 1.32; 95\% CI: 0.77-2.15; p = 0.31) were not significantly associated with OS on multivariate analysis.

TABLE 3. Six-month overall survival rates (OS) of the characteristics included in the WBRT-30-BC and the related scoring points

\begin{tabular}{lcc}
\hline Characteristic & $\begin{array}{c}\text { 6-month } \\
\text { OS rate } \\
\text { (\%) }\end{array}$ & $\begin{array}{c}\text { Scoring } \\
\text { points }\end{array}$ \\
\hline Karnofsky performance score & 8 & 1 \\
$<70 \%$ & 32 & 3 \\
$70 \%$ & 72 & 7 \\
$>70 \%$ & & \\
Time between first diagnosis of breast cancer and WBRT & 29 & 3 \\
$\leq 33$ months & 38 & 4 \\
$\geq 34$ months & & \\
Extra-cerebral metastatic disease & 53 & 5 \\
$\quad$ No & 3 & 3 \\
\hline Yes & 28 & \\
\hline
\end{tabular}

WBRT $=$ whole-brain radiotherapy 
TABLE 4. Overall survival (OS) rates of the four prognostic groups at 3, 6, 9 and 12 months following WBRT; the $\mathrm{p}$-value was received from the Wilcoxon test

\begin{tabular}{lccccc}
\hline Prognostic group & $\begin{array}{c}\text { OS at 3 } \\
\text { months } \\
(\%)\end{array}$ & $\begin{array}{c}\text { OS at 6 } \\
\text { months } \\
(\%)\end{array}$ & $\begin{array}{c}\text { OS at 9 } \\
\text { months } \\
(\%)\end{array}$ & $\begin{array}{c}\text { OS at 12 } \\
\text { months } \\
(\%)\end{array}$ & P-value \\
\hline 6-9 points & 25 & 8 & 5 & 2 & \\
10-12 points & 69 & 41 & 25 & 0 & \\
13-15 points & 87 & 68 & 54 & 47 & $<0.001$ \\
16 points & 100 & 100 & 100 & 83 & \\
\hline
\end{tabular}

Thus, the three characteristics KPS, time between first diagnosis of breast cancer and WBRT and extra-cerebral metastatic disease were used to create the WBRT-30-BC. The 6-months OS rates and the related scoring points are shown in Table 3. The sum of the scoring points for each patient resulted in patient scores ranging between 7 and 16 points. The 6-month OS rates of the patient scores are illustrated in Figure 1. These OS rates led to the following prognostic groups: $7-9$ points $(\mathrm{n}=88)$, $10-12$ points $(n=29), 13-15$ points $(n=47)$ and 16 points $(\mathrm{n}=6)$. The 6 -month OS rates of these groups were $8 \%, 41 \%, 68 \%$ and $100 \%(\mathrm{p}<0.001$, Table 4$)$.

When using the WBRT-30-BC, the PPV of the 7-9 points (= poor prognosis) group to correctly identify patients dying within 6 months following WBRT was $92 \%$ compared to $84 \%$ for a DS-GPA score of $0.0-1.0$ points and $92 \%$ for $4-7$ points in the previous Rades-Score. ${ }^{9,10}$ The PPV of the 16 points (= most favorable prognosis) group of the WBRT30-BC to correctly identify patients surviving for at least 6 months following WBRT was 100\% compared to $74 \%$ for a DS-GPA score of $\geq 3.0$ points and $68 \%$ for 12 points in the previous Rades-Score. 9,10 For the DS-GPA, $\geq 3.0$ points were used, since only one patient had a DS-GPA score of $>3.0$. This patient died four months after WBRT.

\section{Discussion}

Cerebral metastases are quite common in breast cancer patients. ${ }^{1,2} \mathrm{~A}$ considerable number of these patients have relatively favorable survival prognoses and will live long enough to experience late treatment-related toxicity including neuro-cognitive decline. ${ }^{1}$ Therefore, in comparison to several other primary tumors more patients with a limited number of cerebral lesions receive treatment with a local therapy alone such as neurosurgical resection and radiosurgery. However, many patients with cerebral metastases from breast cancer are still assigned to WBRT alone, particularly those with

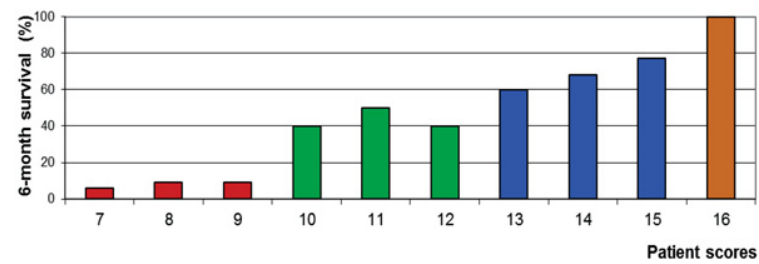

FIGURE 1. The 6-month overall survival rates related to the scoring points that range from 7 to 16 points.

more than five lesions, poor general condition and high co-morbidity index. ${ }^{1}$

In patients with a longer expected survival, WBRT with total doses exceeding 30 Gy in 10 fractions and doses per fraction of less than 3 Gy are recommended. ${ }^{5,6}$ According to the findings of a retrospective study of 186 patients with a median OS time of 15 months, $40 \mathrm{~Gy}$ in 20 fractions resulted in significantly $(p=0.007)$ better OS than 30 Gy in 10 fractions at 1 year $(61 \%$ versus $50 \%) .{ }^{5}$ Cerebral control rates were $44 \%$ versus $28 \%$, respectively ( $p=$ $0.064)$. Since the risk of developing neuro-cognitive deficits increases with lifetime, longer-term surviving patients should not be treated with doses per fraction of 3 Gy or higher. ${ }^{6}$ The risk of neurocognitive decline may also be reduced with sparing of the hippocampal neural stem-cell compartment and administration of memantine. ${ }^{7,8}$

In contrast to longer-term survivors, patients with a very short remaining lifespan should receive WBRT with a short overall treatment time to avoid that they spend more time than necessary on a radiation oncology ward or with transports to the radiation oncology department. ${ }^{1} 20 \mathrm{~Gy}$ in 5 fractions appears a reasonable option, since it was not inferior to $30 \mathrm{~Gy}$ in 10 fractions in a previous study with more than three cerebral lesions. ${ }^{3}$ For selected patients with a very short expected lifespan, best supportive care (BSC) alone can be considered, since in a randomized trial of poor prognosis nonsmall lung cancer patients with brain metastases, BSC alone was not significantly inferior to BSC plus 20 Gy in 5 fractions with respect to qualityadjusted life-years. ${ }^{4}$

Thus, to select the optimal WBRT regimen, estimation of the patient's OS prognosis appears crucial. Several instruments were developed in cohorts of patients receiving WBRT including the recursive partitioning analysis (RPA) classification, the graded prognostic assessment (GPA) classification and the WBRT-30.12,14,15 Patients used to develop the RPA and GPA classifications had received various treatments such as different WBRT-regimens 
including hyperfractionation, WBRT plus misonidazole and WBRT plus chemotherapy. ${ }^{14,15}$ For the development of the GPA classification, additionally patients treated with WBRT plus radiosurgery boost were included. ${ }^{15}$ Thus, the creation of both RPA and GPA classification might have been influenced by treatment-related biases. The WBRT-30 score was created in a homogeneously treated cohort; all patients received WBRT alone with 30 Gy in 10 fractions. ${ }^{12}$ This may have led to the fact that the WBRT-30 score demonstrated the highest accuracy of the three tools for correctly predicting death within 6 months (PPV of 97\% versus 92\% and $85 \%$ ) and survival for at least 6 months (PPV of $96 \%$ versus $75 \%$ and $64 \%$ ) following treatment. ${ }^{12}$

The next step to provide optimal personalization for patients with cerebral metastases is the creation of specific survival scores for single tumor entities. For breast cancer patients, such tools already exist. ${ }^{9,10}$ However, like most previous scores they were developed in heterogeneously treated series of patients. Considering the high accuracy of the general WBRT-30 score in predicting death within 6 months and survival for at least 6 months, we developed a WBRT-30 score particularly for breast cancer patients (WBRT-30-BC) in this study. ${ }^{15}$ The WBRT-30-BC included four predictive groups with significantly different 6-month OS rates. When compared to the DS-GPA and the Rades-Score, the PPV of the WBRT-30-BC to identify patients who will die within 6 months after WBRT of $92 \%$ was higher than for the DS-GPA ( $84 \%)$ and the same as for the Rades-Score (92\%), ${ }^{9,10}$ Regarding the PPV to identify patients who will live 6 months or longer after WBRT, the WBRT-30-BC (100\%) was superior to both DS-GPA (74\%) and Rades-Score (68\%).

Thus, the WBRT-30-BC appears preferable to the other two instruments. However, when using the WBRT-30-BC, one should be aware that the data used to create it were retrospective in nature. Patients of the 7-9 points group had a very poor OS and, therefore, should be treated with $20 \mathrm{~Gy}$ in 5 fractions plus BSC or, in selected cases, with BSC alone. ${ }^{3,4}$ The OS prognoses of the 10-12 points group can be considered intermediate, and WBRT with 30 Gy in 10 fractions might be a reasonable option. Of the patients of the 13-15 points group $68 \%$ survived for at least 6 months and $47 \%$ for at least 12 months (Table 4). Considering this relatively favorable prognosis, these patients appear good candidates for longer-course WBRT with lower doses per fraction and may even benefit from total doses $>30$ Gy.5,6 Patients of the 16 points group had very favorable OS prognoses with 6-month and 12 -months OS probabilities of $100 \%$ and $83 \%$, respectively. If assigned to WBRT, these patients should be treated with $40 \mathrm{~Gy}$ in 20 fractions of 2 Gy. ${ }^{5}$ Moreover, patients of the latter two groups (13-15 points and 16 points) should be considered for hippocampal sparing WBRT and treatment with memantine during WBRT to optimally decrease the risk of neuro-cognitive decline. ${ }^{7,8}$

In summary, the new WBRT-30-BC appeared very accurate in predicting death within 6 months and survival for at least 6 months of breast cancer patients receiving WBRT. The new score was superior to previous instruments in predicting survival for at least 6 months following WBRT. It can contribute to the development of personalized treatments and may be valuable for clinical trials (stratification) in the future.

\section{References}

1. Tsao MN, Rades D, Wirth A, Lo SS, Danielson BL, Gaspar LE, et al. Radiotherapeutic and surgical management for newly diagnosed brain metastasis(es): an American Society for Radiation Oncology evidencebased guideline. Pract Radiat Oncol 2012; 2: 210-25. doi: 10.1016/j. clon.2012.03.008

2. Siegel RL, Miller KD, Jemal A. Cancer statistics, 2019. CA Cancer J Clin 2019; 69: 7-34. doi: 10.3322/caac.21551

3. Rades D, Kieckebusch S, Lohynska R, Veninga T, Stalpers $\amalg$, Dunst J, et al Reduction of overall treatment time in patients irradiated for more than three brain metastases. Int J Radiat Oncol Biol Phys 2007; 69: 1509-13.

4. Mulvenna P, Nankivell M, Barton R, Faivre-Finn C, Wilson P, McColl E, et al. Dexamethasone and supportive care with or without whole brain radiotherapy in treating patients with non-small cell lung cancer with brain metastases unsuitable for resection or stereotactic radiotherapy (QUARTZ): results from a phase 3, non-inferiority, randomised trial. Lancet 2016; 388: 2004-14. doi: 10.1016/S0140-6736(16)30825-X

5. Rades D, Panzner A, Dziggel L, Haatanen T, Lohynska R, Schild SE. Doseescalation of whole-brain radiotherapy for brain metastasis in patients with a favorable survival prognosis. Cancer 2012; 118: 3853-9. doi: 10.1002/ cncr.26680

6. DeAngelis LM, Delattre JY, Posner JB. Radiation-induced dementia in patients cured of brain metastases. Neurology 1989; 39: 789-96.

7. Gondi V, Pugh SL, Tome WA, Caine C, Corn B, Kanner A, et al. Preservation of memory with conformal avoidance of the hippocampal neural stem-cell compartment during whole-brain radiotherapy for brain metastases (RTOG 0933): a phase II multi-institutional trial. J Clin Oncol 2014; 32: 3810-6. doi: 10.1200/JCO.2014.57.2909

8. Brown PD, Pugh S, Laack N, Wefel JS, Khuntia D, Meyers C, et al.; Radiation Therapy Oncology Group (RTOG): Memantine for the prevention of cognitive dysfunction in patients receiving whole-brain radiotherapy: a randomized, double-blind, placebo-controlled trial. Neuro Oncol 2013; 15: 1429-37. doi: 10.1093/neuonc/not114

9. Sperduto PW, Chao ST, Sneed PK, Luo X, Suh J, Roberge D, et al. Diagnosisspecific prognostic factors, indexes, and treatment outcomes for patients with newly diagnosed brain metastases: a multi-institutional analysis of 4,259 patients. Int J Radiat Oncol Biol Phys 2010; 77: 655-61. doi: 10.1016/j. ijrobp.2009.08.025

10. Rades D, Dziggel L, Segedin B, Oblak I, Nagy V, Marita A, et al. A simple survival score for patients with brain metastases from breast cancer. Strahlenther Onkol 2013; 189: 664-7. doi: 10.1007/s00066-013-0367-5

11. Kaplan EL, Meier P. Non parametric estimation from incomplete observations. J Am Stat Assoc 1958; 53: 457-81. 
12. Rades D, Dziggel L, Nagy V, Segedin B, Lohynska R, Veninga T, et al. A new survival score for patients with brain metastases who received wholebrain radiotherapy (WBRT) alone. Radiother Oncol 2013; 108: 123-7. doi: 10.1016/j.radonc.2013.06.009

13. Mehta MP, Rodrigus P, Terhaard CH, Rao A, Suh J, Roa W, et al. Survival and neurologic outcomes in a randomizedtrial of motexafin gadolinium and whole-brain radia-tion therapy in brain metastases. J Clin Oncol 2003; 21 . 2529-36. doi: 10.1200/JCO.2003.12.122

14. Gaspar L, Scott C, Rotman M, Asbell S, Phillips T, Wasserman T, et al. Recursive partitioning analysis (RPA) of prognostic factors in three Radiation Therapy Oncology Group (RTOG) brain metastases trials. Int J Radiat Oncol Biol Phys 1997; 37: 745-51.

15. Sperduto PW, Berkey B, Gaspar LE, Mehta M, Curran W. A new prognostic index and comparison to three other indices for patients with brain metastases: an analysis of 1,960 patients in the RTOG database. Int J Radiat Oncol Biol Phys 2008; 70: 510-4. doi: 10.1016/j.ijrobp.2007.06.074 